\title{
Effect of sialyllactose on growth performance and intestinal epithelium functions in weaned pigs challenged by enterotoxigenic Escherichia Coli
}

Qiming Duan ${ }^{1,2}$, Daiwen Chen ${ }^{1,2}$, Bing Y Y ${ }^{1,2}$, Zhiqing Huang ${ }^{1,2}$, Yuheng Luo ${ }^{1,2}$, Ping Zheng ${ }^{1,2}$, Xiangbing Mao ${ }^{1,2}$, Jie $\mathrm{Yu}^{1,2}$, Junqiu Luo ${ }^{1,2}$, Hui $\mathrm{Yan}^{1,2}$ and Jun $\mathrm{He}^{1,2^{*}}$ (i)

\begin{abstract}
Background: Sialyllactose (SL) is one of the most abundant oligosaccharides present in porcine breast milk. However, little is known about its effect on growth performance and intestinal health in weaned pigs. This study was conducted to explore the protective effect of SL on intestinal epithelium in weaned pigs upon enterotoxigenic Escherichia coli (ETEC) challenge.

Methods: Thirty-two pigs were randomly divided into four treatments. Pigs fed with a basal diet or basal diet containing SL $(5.0 \mathrm{~g} / \mathrm{kg})$ were orally infused with ETEC or culture medium.

Results: SL supplementation elevated the average daily gain (ADG) and feed efficiency in the ETEC-challenged pigs $(P<0.05)$. SL also improved the digestibilities of dry matter $(D M)$, gross energy $(G E)$, and ash in non-challenged pigs $(P<0.05)$. Moreover, $S L$ not only elevated serum concentrations of immunoglobulins ( $\lg A$, $\lg G$, and $\lg M)$, but also significantly decreased the serum concentrations of inflammatory cytokines (TNF- $\alpha$, IL-1 $\beta$, and IL-6) upon ETEC challenge $(P<0.05)$. Interestingly, SL increased the villus height, the ratio of villus height to crypt depth $(\mathrm{V}: \mathrm{C})$, and the activities of mucosal sucrase and maltase in the jejunum and ileum $(P<0.05)$. SL also elevated the concentrations of microbial metabolites (e.g. acetic acid, propanoic acid, and butyric acid) and the abundance of Lactobacillus, Bifidobacterium, and Bacillus in the cecum $(P<0.05)$. Importantly, SL significantly elevated the expression levels of jejunal zonula occludins-1 (ZO-1), occluding, and fatty acid transport protein-4 (FATP4) in the ETEC-challenged pigs $(P<0.05)$.

Conclusions: SL can alleviate inflammation and intestinal injury in weaned pigs upon ETEC challenge, which was associated with suppressed secretion of inflammatory cytokines and elevated serum immunoglobulins, as well as improved intestinal epithelium functions and microbiota.
\end{abstract}

Keywords: Immunity, Inflammation, Intestinal epithelium, Sialyllactose, Weaned pigs

\footnotetext{
* Correspondence: hejun8067@163.com

${ }^{1}$ Institute of Animal Nutrition, Sichuan Agricultural University, Sichuan

Province, Chengdu 611130, People's Republic of China

${ }^{2}$ Key Laboratory of Animal Disease-resistant Nutrition, Sichuan Province,

Chengdu 611130, People's Republic of China
}

C The Author(s). 2022 Open Access This article is licensed under a Creative Commons Attribution 4.0 International License, which permits use, sharing, adaptation, distribution and reproduction in any medium or format, as long as you give appropriate credit to the original author(s) and the source, provide a link to the Creative Commons licence, and indicate if changes were made. The images or other third party material in this article are included in the article's Creative Commons licence, unless indicated otherwise in a credit line to the material. If material is not included in the article's Creative Commons licence and your intended use is not permitted by statutory regulation or exceeds the permitted use, you will need to obtain permission directly from the copyright holder. To view a copy of this licence, visit http://creativecommons.org/licenses/by/4.0/. The Creative Commons Public Domain Dedication waiver (http://creativecommons.org/publicdomain/zero/1.0/) applies to the data made available in this article, unless otherwise stated in a credit line to the data. 


\section{Background}

Weaning is one of the most stressful events for neonatal pigs, as weaning deprives their protections from maternal passive immunity and may contribute to intestinal and immune system dysfunctions that lead to reduced growth and feed intake, particularly during the first week after weaning [1]. Post weaning diarrhea (PWD) is a common problem in pig production, and enterotoxigenic Escherichia coli (ETEC) has been considered to be the main bacterial cause of PWD and intestinal injury (accounts for more than $45 \%$ of piglet diarrhea). Previous study indicated that ETEC can adhere to intestinal epithelial cells and cause intestinal injury through endotoxin and exotoxin [2, 3]. In past decades, antibiotics have been widely used as therapeutic drugs for ETEC infection to prevent diarrhea and intestinal injury in pig production [4]. However, the abuse of antibiotics can lead to bacterial resistance and drug residues in animal products [5]. Therefore, developing of substitutes for traditionally used antibiotics has attracted considerable research interest worldwide.

Breast milk has been considered to be the most ideal food for neonatal animals including pigs, as it contains nearly all necessary nutrients for neonatal animals [6]. Moreover, the breast milk contains a variety of bioactive substances such as antibacterial peptides, growth factors, and oligosaccharides [7]. Milk oligosaccharides (MOs) are an important component of mammalian milk carbohydrate, and are the third largest component in breast milk [8]. Currently, increasing evidence is generated for specific functions of specific MOs, being anti-adhesive, immune-modulating, or a targeted prebiotic for specific desirable bacterial/microbiota strains in early infant development [9]. MOs are composed of the five monosaccharides glucose (Glc), galactose (Gal), Nacetylglucosamine (GlcNAc), fucose (Fuc) and sialic acid (Sia). Sialyllactose (SL), which is the most abundant components of milk oligosaccharides [10] and is a compound where the $\mathrm{N}$-acetyl-D-neuraminic acid (Neu5Ac or SA) unit is connected to the galactose unit of lactose and essentially it is a sialic acid bound to the lactose molecule [11]. Previous studies indicate that MOs can improve baby's health and development by promoting the growth of intestinal beneficial microflora (e.g. Bifidobacterium and Bacillus) [12], serving as anti-adhesive antimicrobials to directly reduce microbial infections [13], and providing sialic acid to help brain development [14]. Moreover, MOs can also be used to protect piglets against rotavirus infection and shorten the duration of diarrhea [15].

Although, there are many studies on milk oligosaccharides, the effect of SL on growth performance and intestinal epithelial functions in weaned pigs is just beginning to be explored. This study was conducted to explore whether SL supplementation could attenuate intestinal inflammation and epithelium injury in weaned pigs induced by ETEC. This study will also provide convincing evidence on the beneficial effect of milk oligosaccharides and offer key insights into its potential mechanisms of action.

\section{Materials and methods}

\section{Bacterial strains and culture}

Pathogenic Escherichia coli (ETEC) was purchased from China veterinary culture collection center (CVCC, Beijing, China). The serotype of ETEC was o149: K91, $\mathrm{k} 88 \mathrm{ac}$, and the strain number of CVCC was 225. It was a vacuum freeze-dried strain. The ETEC with strong toxicity was produced through resuscitation and proliferation culture in our laboratory. Luria-Bertani (LB) and LB agar broth were prepared (Yeast Extract, $0.5 \mathrm{~g} ; \mathrm{NaCl}, 1 \mathrm{~g}$; Peptone, $1 \mathrm{~g}$; double-distilled water, $50 \mathrm{~mL}$; agar powder, $2 \%$ for LB agar broth) and sterilized under $121^{\circ} \mathrm{C}, 0.11$ $\mathrm{MPa}$ for $20 \mathrm{~min}(\mathrm{pH}=6)$. The bacteria were resuscitated in $3 \mathrm{~mL}$ of Luria Bertani (LB) broth at $37^{\circ} \mathrm{C}$ with shaking for $24 \mathrm{~h}$ and inoculated on LB agar. A single colony was inoculated into $50 \mathrm{~mL}$ of LB broth, cultured overnight at $37^{\circ} \mathrm{C}$ and $250 \mathrm{rpm}$, then subcultured and serially diluted on LB agar for bacterial counts [16].

\section{Experimental design and diet}

A total of 32 male Duroc $\times$ Landrace $\times$ Yorkshire pigs weaned at 21 days of age (with an average body weight of $6.66 \pm 0.14 \mathrm{~kg}$ ) were selected and randomly allotted into a $2(\mathrm{SL}) \times 2$ (ETEC) factorial experiment of four treatments composed of $\mathrm{CON}$ (pigs were fed with a basal diet), CSL (pigs were fed with basal diet containing $5 \mathrm{~g} / \mathrm{kg}$ SL product), ECON (pigs were fed with a basal diet and challenged by ETEC), ESL (pigs were fed with basal diet containing $5 \mathrm{~g} / \mathrm{kg}$ SL product and challenged by ETEC). Sialylactose (SL, $\geq 95 \%$ ) was obtained from Glycom A/S. SL is produced via microbial fermentation and is a trisaccharide made from glucose, galactose and $\mathrm{N}$-acetylneuraminic acid. The concentration of SL in the diet is $5 \mathrm{~g} / \mathrm{kg}$, which was decided according to the oligosaccharides content in the mature milk of sow's (5 to 10 $\mathrm{g} / \mathrm{L})$ and previous study on piglets [17]. Pigs were received the same parental nutrition and management (e.g. sows were fed with the same diet, synchronization estrous). The trial last for $28 \mathrm{~d}$. On $\mathrm{d} \mathrm{26}$, the challenge groups were orally treated with $100 \mathrm{~mL}$ of LB culture containing $1 \times 10^{10} \mathrm{CFU} / \mathrm{mL}$ of ETEC by using an orogastric tube last for $3 \mathrm{~d}$, whereas the non-challenge groups were orally treated with equivalent amount of culture medium [18]. The basal diet (Table 1) was formulated to meet the swine nutrient requirements recommended by National Research Council (NRC, 2012) [19]. Pigs were individually housed in $1.5 \times 0.7 \mathrm{~m}^{2}$ metabolism cage and 
Table 1 Experiment basal diet composition and nutrient level

\begin{tabular}{|c|c|c|c|}
\hline Ingredients & $\%$ & Nutrient level & contents \\
\hline Corn & 28.31 & Digestible energy, calculated, MJ/kg & 14.78 \\
\hline Extruded corn & 24.87 & Crude Protein, \% & 19.68 \\
\hline Soybean meal & 8.50 & Calcium, \% & 0.81 \\
\hline Extruded full-fat soybean & 10.30 & Available phosphorus, $\%$ & 0.55 \\
\hline Fish meal & 4.20 & Lysine, \% & 1.35 \\
\hline Whey powder & 7.00 & Methionine, \% & 0.42 \\
\hline Soybean protein concentrate & 8.00 & Methionine + cysteine, \% & 0.60 \\
\hline Soybean oil & 2.00 & Threonine, \% & 0.79 \\
\hline Sucrose & 4.00 & Tryptophan, \% & 0.22 \\
\hline Limestone & 0.90 & & \\
\hline Dicalcium phosphate & 0.50 & & \\
\hline $\mathrm{NaCl}$ & 0.30 & & \\
\hline L-Lysine $\mathrm{HCl}, 78 \%$ & 0.47 & & \\
\hline DL-Methionine & 0.15 & & \\
\hline L-Threonine, 98.5\% & 0.13 & & \\
\hline Tryptophan, 98\% & 0.03 & & \\
\hline Chloride choline & 0.10 & & \\
\hline Vitamin premix $^{1}$ & 0.04 & & \\
\hline Mineral premix ${ }^{2}$ & 0.20 & & \\
\hline Total & 100 & & \\
\hline
\end{tabular}

were given ad libitum access to feed and fresh water with the room temperature controlled between 25 and $28{ }^{\circ} \mathrm{C}$, relative humidity $65 \% \pm 5 \%$.

\section{Sample collection}

Feed samples were collected at the beginning of the experiment and stored at $-20^{\circ} \mathrm{C}$ for nutrient analysis, during the $\mathrm{d} 22-25$ of the experiment, fresh fecal samples were collected immediately after excretion from pigs in each cage, weighed, and adding $10 \mathrm{~mL}$ $10 \% \mathrm{H}_{2} \mathrm{SO}_{4}$ solution to per $100 \mathrm{~g}$ of fresh fecal. The feed and fecal samples were dried at $65^{\circ} \mathrm{C}$ for $2 \mathrm{~d}$, and ground to pass through a 1-mesh screen, and then stored at $-20^{\circ} \mathrm{C}$ until measurement for nutrients digestibility. Blood samples were obtained on d 22 by jugular vein puncture and placed in two $10-\mathrm{mL}$ vacuum tubes. One for blood parameters analyzed and the serum was collected after centrifugation of another tube at $3500 \times g$ and stored at $-20^{\circ} \mathrm{C}$ until the serum indexes analysis. Pigs were anesthetized by intravenous injection with sodium pentobarbital (200 $\mathrm{mg} / \mathrm{kg} \mathrm{BW}$ ), and the tissues of the duodenum, jejunum and ileum were immediately isolated at the end of the trial. At the same time, the duodenum, jejunum and middle ileum $(4 \mathrm{~cm}$ from the middle of each intestine) were gently rinsed with cold phosphate buffered saline (PBS), and then fixed in $4 \%$ paraformaldehyde solution for morphological analysis. In addition, the cecal digestive products were collected, and the intestinal mucosa was obtained from the residual intestinal segments with a scalpel blade and placed in a freezing tube, then frozen by immersion in liquid nitrogen, and stored at $-80^{\circ} \mathrm{C}$ until analysis.

\section{Apparent total tract nutrient digestibility analysis}

The frozen dried and milled feed and fecal samples were used for nutrient digestibility analysis, which uses acid insoluble ash (AIA) as endogenous indicators. The dry matter (DM), crude protein (CP), ether extract (EE) and ash contents were determined according to AOAC [20], whereas the GE content was measured by an adiabatic bomb calorimeter (LECO, St. Joseph, Michigan, USA) to calculate the apparent total tract digestibility. All contents were calculated by following formula: (100-A1F2/ A2F1 × 100) [21] A1: digesta nutrient; A2: digesta AIA; F1: diet AIA; F2: digesta AIA. 


\section{Serum proinflammatory cytokines and immunoglobulin detection}

The concentration of proinflammatory cytokines (TNF$\alpha$, IL-1 $\beta$ and IL-6) and immunoglobulin (IgG, IgM, and IgA) in serum were determined followed by the instructions of a commercial available porcine Enzyme-Linked Immunosorbent Assay (ELISA) kits (Shanghai Meimian Biotechnology Co., Ltd., Shanghai, China). All procedures were guided by manuals of the kits. For quantification, the standards provided in the kits were used to generate standard curves.

\section{Histomorphology analysis of intestinal segment}

The fixed with $4 \%$ paraformaldehyde intestinal segments were dehydrated through a graded series of ethanol and then embedded in paraffin [21]. Cross-sections of each sample were prepared, stained with hematoxylin and eosin (H\&E), and then sealed with neutral resin. Finally, ultrathin sections of the duodenal, jejunal and ileal samples were examined for crypt depth and villus height with image processing and analysis system (Image-Pro Plus 6.0). The method of measurement of crypt depth and villus height was followed by King's and Wan's. A total of 10 intact, well-oriented, crypt-villus units were analyzed in triplicate per intestinal segment [22, 23]. Calculate the ratio of villus height to crypt depth $(\mathrm{V}: \mathrm{C})$ from the above data.

\section{Enzyme activity}

The frozen duodenal, jejunal and ileal mucosa were homogenized in chilled saline at a ratio of 1:9 $(\mathrm{w} / \mathrm{v})$ for 15 $\min$. The homogenate was centrifuged at $3500 \times g$ for $10 \mathrm{~min}$ at $4{ }^{\circ} \mathrm{C}$ and the supernatant was used to determine the enzyme activities. The activity of alkaline phosphatase (AKP) was determined using the alkaline phosphatase assay kit (A059-2-2) purchased from Nanjing Jiancheng Biotechnology Co., Ltd. (Nanjing, China). The enzyme-linked immunosorbent assay (ELISA) kits purchased from Shanghai Enzyme-linked Biotechnology Co., Ltd. (Shanghai, China) were used for detections of lactase (Porcine Lactase ELISA Kit ml712060), sucrase (Porcine Sucrase ELISA Kit ml712026), and maltase (Porcine Maltase ELISA Kit ml712030). All procedures were carried out according to the instructions of the kits. The absorbance of each reaction was determined using the spectrophotometer (UV-VIS Spectrophotometer, Leng Guang SFZ1606017568, Shanghai, China.) at a wavelength of $450 \mathrm{~nm}$. Enzyme activity was defined as hydrolysis of $1 \mathrm{~mol}$ of the substrate per $\mathrm{mg}$ of protein tissue per minute under the condition of $37^{\circ} \mathrm{C}, \mathrm{pH}=6.0$.

\section{Caecal microbiological analysis}

Approximately $200 \mathrm{mg}$ caecal digesta was weighed and treated using the Stool DNA Kits (Omega Bio-Tek,
Doraville, CA, USA) following the manufacturer's instruction to extract total DNA for quantification realtime PCR, which was performed by conventional PCR on the Opticon DNA Engine (Bio-Rad). Total bacteria were detected by the reaction which runs in a volume of $25 \mu \mathrm{L}$ with $1 \mu \mathrm{L}$ of forward and $1 \mu \mathrm{L}$ of reverse primers $(100 \mathrm{nmol} / \mathrm{L}), 12.5 \mu \mathrm{L}$ SYBR Premix Ex Taq $(2 \times$ concentrated), $2 \mu \mathrm{L}$ template DNA, $1 \mu \mathrm{L} 50 \times$ ROX Reference Dye*3 and $7.5 \mu \mathrm{L}$ of RNase-Free $\mathrm{ddH}_{2} \mathrm{O}$. The SuperReal PreMix (Probe) kit (Tiangen Biotech Co., Ltd., Beijing, China) was used for Lactobacillus, E. coli, Bacillus and Bifidobacterium detection and primers and fluorescent oligonucleotide probes presented in Table S1. Each reaction was run in a volume of $25 \mu \mathrm{L}$ with $12.5 \mu \mathrm{L} 2 \times$ Super Real PreMix (Probe), $1 \mu \mathrm{L}$ of forward and $1 \mu \mathrm{L}$ of reverse primers $(100 \mathrm{nmol} / \mathrm{L}), 1 \mu \mathrm{L} 50 \times$ ROX Reference Dye*3, $1 \mu \mathrm{L}$ probe $(100 \mathrm{nmol} / \mathrm{L}), 2 \mu \mathrm{L}$ DNA and $6.5 \mu \mathrm{L}$ of RNase-Free $\mathrm{ddH}_{2} \mathrm{O}$. All reaction protocol was composed of one cycle of pre-denaturation at $95^{\circ} \mathrm{C}$ for $15 \mathrm{~min}$; forty cycles of denaturation at $95^{\circ} \mathrm{C}$ for $3 \mathrm{~s}$; annealing and extension at $60^{\circ} \mathrm{C}$ for $30 \mathrm{~s}$. The Cycle threshold $(\mathrm{Ct})$ values and baseline settings were determined by automatic analysis settings, and the copy numbers of the target group for each reaction were calculated from the standard curves, which were generated by constructing standard plasmids by a 10 -fold serial dilution of plasmid DNA $\left(1 \times 10^{1}\right.$ to $1 \times 10^{9}$ copies $\left./ \mu \mathrm{L}\right)$.

\section{Metabolite concentrations in cecal digesta}

The SCFA (acetic acid, propionic acid, and butyric acid) concentrations were determined using a gas chromatograph system (VARIAN CP-3800, Varian, Palo Alto. CA, USA; capillary column $30 \mathrm{~m} \times 0.32 \mathrm{~mm} \times 0.25 \mu \mathrm{m}$ film thickness) following previous method [24]. After vortex, the digesta was centrifuged at $4{ }^{\circ} \mathrm{C}$ for $10 \mathrm{~min}(12,000 \times$ $g$ ), and the supernatant $(1 \mathrm{~mL})$ was then transferred into an Eppendorf tube $(2 \mathrm{~mL})$ and mixed with $0.2 \mathrm{~mL}$ metaphosphoric acid. After $30 \mathrm{~min}$ incubation at $4^{\circ} \mathrm{C}$, the tubes were centrifuged at $4{ }^{\circ} \mathrm{C}$ for $10 \mathrm{~min}(12,000 \times g)$ and aliquots of the supernatant $(1 \mu \mathrm{L})$ were analyzed using the $\mathrm{GC}$ with a flame ionization detector and an oven temperature of $100-150{ }^{\circ} \mathrm{C}$. The polyethylene glycol column was operated with highly purified N2 as the carrier gas at $1.8 \mathrm{~mL} / \mathrm{min}$.

\section{Isolation and reverse transcription of RNA and q-PCR}

The frozen duodenal, jejunal and ileal mucosa samples (about $0.1 \mathrm{~g}$ ) were ground in liquid nitrogen and homogenized in $1 \mathrm{~mL}$ of RNAiso Plus (Takara Biotechnology Co., Ltd., Dalian, China) to extract total RNA followed the manufacturer's instructions, and the purity and concentration of total RNA were detected by using a spectrophotometer (NanoDrop 2000, Thermo Fisher Scientific, Inc., Waltham, MA, USA), samples which 
OD260/OD280 ratio ranged from 1.8 to 2.0 were deemed appropriate. Subsequently, a volume equivalent to $1 \mu \mathrm{g}$ total RNA from each duodenal, jejunal, and ileal sample was used for reverse transcription into cDNA, which based on the protocol of PrimeScript ${ }^{\mathrm{tm}} \mathrm{RT}$ reagent kit with gDNA Eraser (Takara Biotechnology Co., Ltd., Dalian, China). This process consists of two steps: I: $37^{\circ} \mathrm{C}$ for 15 min, II: $85^{\circ} \mathrm{C}$ for $5 \mathrm{~s}$.

The expression level of the target gene in intestinal mucosa was quantified using $\mathrm{q}-\mathrm{PCR}$, the oligonucleotide primers sequences used in $\mathrm{q}-\mathrm{PCR}$ were presented in Table S1, qPCR was performed with the $\mathrm{SYBR}^{\circ}$ Green PCR I PCR reagents (Takara Bio Inc., Dalian, China) using a CFX96 Real-Time PCR Detection System (BioRad Laboratories, Hercules, CA, USA). All cDNA samples were detected in triplicate. The reaction mixture $(10 \mu \mathrm{L})$ contained $5 \mu \mathrm{L}$ SYBR Premix Ex Taq II (Tli RNaseH Plus), $0.5 \mu \mathrm{L}$ forward primer, $0.5 \mu \mathrm{L}$ reverse primer, $1 \mu \mathrm{L} \mathrm{cDNA}$ and $3 \mu \mathrm{L}$ RNase-Free water. The protocol used in q-PCR was as followed: $95^{\circ} \mathrm{C}$ for $30 \mathrm{~s}$, followed by 40 cycles: at $95^{\circ} \mathrm{C}$ for $5 \mathrm{~s}$ and $60^{\circ} \mathrm{C}$ for $34 \mathrm{~s}$. The generated Gene-specific amplification products were confirmed by melting curve analysis after each real-time quantitative PCR assay. The housekeeping gene $\beta$-actin was used to standardize the mRNA expression level of target genes, which calculated based on the $2^{-\Delta \Delta C t}$ method [25].

\section{Sample size calculation and statistical analysis}

The minimal sample size was calculated based on the experimental design (repeated-measures, between factors ANOVA) determining the SL $\times$ ETEC effect to the intestinal health as the primary outcome measure. We used G*Power software (version 3.1.9.2) for the power analysis with following variables; the power $=0.8$, significant level $=0.05$, and effect size $=$ 0.35 in the experiment. The effect size was estimated based on the results from a preliminary study. Hence, the required minimal sample size was five pigs per group.

The data collected before the ETEC challenge was analyzed by one-way ANOVA. After the challenge, the data were analyzed by two-way ANOVA with the General Linear Model (GLM) procedure of SPSS as a 2 $(\mathrm{SL}) \times 2 \quad($ ETEC $)$ factorial design. $P$-value $<0.05$ was deemed to be significant and the $P$-value between 0.05 and 0.1 to show a significant trend. Duncan's multiple range test was used based on the analysis of ANOVA, which showed a significant difference. All data were analyzed by SPSS 24.0 (IBM, Chicago, IL, USA) and GraphPad (version 9) software (GraphPad Software Inc., CA, USA). Results are expressed as means with their standard errors.

\section{Results}

Effect of SL on growth performance and nutrients digestibility in weaned pigs upon ETEC challenge

As shown in Table 2, ETEC challenge decreased ADG and increased F:G in the weaned pigs $(P<0.05)$. Moreover, we observed a trend toward an interaction effect of $\mathrm{SL}$ and ETEC, when this trend toward an interaction effect was investigated with post-hoc test, we found that while the ETEC increased the F:G, this effect was prevented by the SL treatment. SL increased the digestibilities of DM, Ash, and GE in non-challenged pigs $(P<$ 0.05). The digestibility of Ash was also higher in the ESL group than in the ECON group $(P<0.05)$ (Table 3$)$.

\section{Effect of SL on serum immunogloblins and inflammatory cytokines in weaned pigs upon ETEC challenge}

As shown in Fig. 1, ETEC challenge significantly decreased the serum concentrations of IgA, IgG, and IgM $(P<0.05)$. However, SL supplementation increased their concentrations in the non-challenged pigs $(P<0.05)$. A trend toward an interaction effect of SL and ETEC was observed that the decreasing of IgA upon ETEC challenged was prevented by the SL treatment. The serum inflammatory cytokines such as the TNF- $\alpha$ and IL- $1 \beta$ were higher in the ECON group than in the $\mathrm{CON}$ group $(P<0.05)$. However, SL supplementation significantly decreased their concentrations in the ETEC-challenged pigs $(P<0.05)$ and increased the IL- 6 concentration in non-challenged pigs.

\section{Effect of SL supplementation on intestinal morphology and mucosal enzyme activity in weaned pigs upon ETEC challenge}

As shown in Table 4 and Fig. 2, ETEC challenge decreased the villus height in the jejunum and ileum $(P<$ $0.05)$. However, SL supplementation significantly increased the jejunal villus height in ETEC-challenged pigs $(P<0.05)$. For the V:C, ETEC challenge significantly decreased ratio of $\mathrm{V}: \mathrm{C}$ in the duodenum, jejunum, and ileum $(P<0.05)$. Moreover, two trends toward an interaction effect of SL and ETEC in ileum were observed, when these trends toward an interaction effect were investigated with post-hoc test, we observed that while the ETEC increased the crypt depth and decreased V:C, these effects were prevented by the SL treatment $(P<$ 0.05). As shown in Table 5, ETEC challenge decreased the activities of maltase and lactase in the duodenal and ileal mucosa, respectively. However, SL supplementation significantly elevated their activities in the nonchallenged pigs $(P<0.05)$. Moreover, the sucrase activity in the duodenal, jejunal and ileal mucosa of the CSL group was significantly higher than that in the $\mathrm{CON}$ group $(P<0.05)$. 
Table 2 Effect of SL supplementation on growth performance in weaned pigs upon ETEC challenge

\begin{tabular}{|c|c|c|c|c|c|c|c|c|}
\hline \multirow[t]{2}{*}{ Items } & \multicolumn{4}{|c|}{ Treatments } & \multirow[t]{2}{*}{ SEM } & \multicolumn{3}{|c|}{$P$-value } \\
\hline & CON & CSL & ECON & ESL & & SL & ETEC & Interaction \\
\hline \multicolumn{9}{|l|}{$1-19 d$} \\
\hline ADFI, g/d & 420.50 & 425.06 & 418.43 & 425.59 & 19.07 & & & \\
\hline$A D G, g / d$ & 281.20 & 294.60 & 285.12 & 292.48 & 13.98 & & & \\
\hline$F: G$ & 1.50 & 1.44 & 1.47 & 1.46 & 0.04 & & & \\
\hline \multicolumn{9}{|l|}{$19-21 d$} \\
\hline$A D F I, g$ & $618.50^{\mathrm{ab}}$ & $705.43^{\mathrm{a}}$ & $527.86^{\mathrm{b}}$ & $590.90^{\mathrm{ab}}$ & 26.37 & 0.14 & 0.05 & 0.81 \\
\hline$A D G, g$ & $510.53^{a}$ & $633.33^{\mathrm{a}}$ & $361.33^{b}$ & $516.00^{a}$ & 31.14 & 0.01 & 0.01 & 0.74 \\
\hline $\mathrm{F}: \mathrm{G}$ & $1.21^{\mathrm{b}}$ & $1.11^{\mathrm{b}}$ & $1.46^{\mathrm{a}}$ & $1.15^{\mathrm{b}}$ & 0.09 & 0.02 & 0.08 & 0.08 \\
\hline
\end{tabular}

$A D F I$ average daily feed intake, $A D G$ average daily gain, $F: G$ Feed:Gain ratio

${ }^{1}$ Mean and total SEM are list in Separate columns, $n=8$

$2 \mathrm{a}, \mathrm{b}$, c mean values within a row with unlike superscript letters were significantly different, $P<0.05$

${ }^{3} \mathrm{CON}$, pigs were fed with a basal diet; CSL, pigs were fed with a SL containing diet, $5 \mathrm{~g} / \mathrm{kg}$; ECON, pigs were fed with a basal diet and challenged by ETEC; ESL, pigs were fed with a SL containing diet and challenged by ETEC

Effect of SL supplementation on intestinal microbial populations and metabolites in weaned pigs upon ETEC challenge

As shown in Table 6, ETEC challenge significantly increased the abundance of $E$. coli in the cecum. SL supplementation significantly elevated the abundance of beneficial microbial populations such as the Lactobacillus, Bifidobacterium, and Bacillus in the non-challenged pigs $(P<0.05)$. Moreover, ETEC challenge decreased the concentrations of acetic acid and propanoic acid in the cecum. However, there is a trend that SL supplementation prevented the decreasing concentrations of acetic acid and propanoic acid. SL also elevated the concentration of butyric acid in the non-challenged $(P<0.05)$.

\section{Effect of SL supplementation on expressions of critical} genes involved in intestinal epithelium functions

As shown in Fig. 3, SL supplementation significantly elevated the expression levels of $Z O-1$ and claudin-1 in the duodenal and jejunal epithelium $(P<0.05)$. SL also

Table 3 Effect of SL supplementation on nutrients digestibility in weaned pigs

\begin{tabular}{lllllll}
\hline Items & \multicolumn{2}{l}{ Treatments } & & SEM & P-value \\
\cline { 2 - 5 } & CON & CSL & ECON & ESL & & \\
\hline DM, \% & $88.86^{\mathrm{b}}$ & $91.05^{\mathrm{a}}$ & $89.09^{\mathrm{b}}$ & $90.17^{\mathrm{ab}}$ & 0.31 & $<0.01$ \\
$\mathrm{CP}, \%$ & 86.87 & 89.36 & 86.56 & 87.34 & 0.55 & 0.15 \\
$\mathrm{EE}, \%$ & 66.05 & 72.24 & 66.73 & 71.46 & 1.40 & $<0.01$ \\
Ash, \% & $85.89^{\mathrm{b}}$ & $89.76^{\mathrm{a}}$ & $86.59^{\mathrm{b}}$ & $89.85^{\mathrm{a}}$ & 0.61 & $<0.01$ \\
$\mathrm{GE}, \%$ & $89.45^{\mathrm{b}}$ & $91.31^{\mathrm{a}}$ & $89.13^{\mathrm{b}}$ & $90.62^{\mathrm{ab}}$ & 0.38 & 0.02
\end{tabular}

$D M$ dry matter, $C P$ crude protein, $E E$ ether extract

${ }^{1}$ Mean and total SEM are list in Separate columns, $n=8$

${ }^{2} \mathrm{a}$, b mean values within a row with unlike superscript letters were significantly different, $P<0.05$

${ }^{3} \mathrm{CON}$, pigs were fed with a basal diet; CSL, pigs were fed with a SL containing diet, $5 \mathrm{~g} / \mathrm{kg}$; ECON, pigs were fed with a basal diet and challenged by ETEC.

$E S L$, pigs were fed with a SL containing diet and challenged by ETEC elevated the expression level of occludin in the jejunal epithelium $(P<0.05)$. Interestingly, ETEC challenge decreased the expression level of FATP-4 in the jejunal epithelium. Moreover, SL supplementation also elevated the expression level of jejunal GLUT-2 in the nonchallenged pigs $(P<0.05)$.

\section{Discussion}

It is well known that breastfeeding is the gold standard for infant nutrition. It offers complete nutrients for the newborn as well as many bioactive components that contribute to healthy development of the newborn [26]. Bioactive factors transferred to the infant via breastfeeding including growth factors [27], carbohydrates [28], cells [29], cytokines [30] and immunoglobulins [31]. These bioactive molecules including the MOs were found to shape microbiota composition, modulate gastrointestinal physiology, promote proper development of the immune system, and enhance intestinal barrier function [32]. SL is the major components of the MOs in sows. Previous study indicated that the SL can act as a prebiotic that can promote intestinal development and protect the intestinal epithelium from many harmful pathogens [33]. In the present study, we found that SL not only increased the ADG in the ETEC-challenged pigs, but also increased the digestibility of DM, Ash, and GE in the non-challenged pigs. The result is consistent with previous study [34], and both results suggest a beneficial effect of SL supplementation on the growth performance of the weaned pigs.

Immunoglobulins, also known as antibodies, are glycoprotein molecules produced by plasma cells, which act as a critical part of the immune response by specifically recognizing and binding to particular antigens, such as bacteria or viruses, and aiding in their destruction [35]. In the present study, SL significantly elevated the serum 


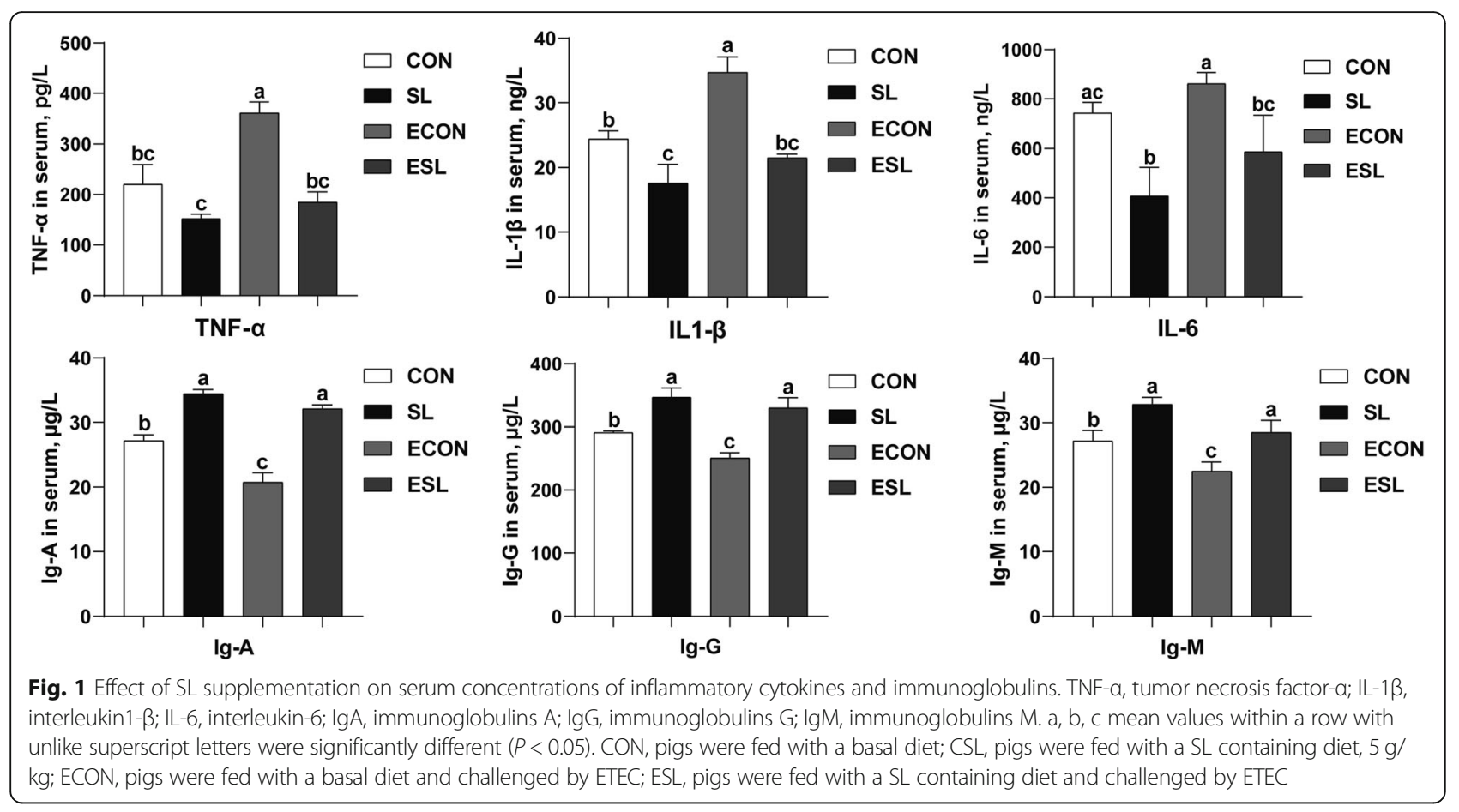

IgA, IgG and IgM concentrations in the ETECchallenged pigs, indicating an enhanced immunity upon SL supplementation. Pro-inflammatory cytokines such as the TNF- $\alpha$ and IL- $1 \beta$ have been shown to mediate host immune function and produce an immune response quickly after pathogenic microorganisms infection [36]. In the present study, ETEC challenge increased serum concentrations of TNF- $\alpha$ and IL-1 $\beta$; however, SL significantly decreased the serum concentrations of TNF- $\alpha$, IL-1 $1 \beta$, and IL-6 in the ETEC-challenged pigs. The result is consistent with previous studies, and both indicated an antiinflammatory property of the MOs [37].

The small intestine is the main place for digestion and absorption, and its integrity determines whether it can function normally. However, ETEC infection can destroy the intestinal structure, and severely impair the intestinal

Table 4 Effect of SL supplementation on intestinal morphology in weaned pigs upon ETEC challenge

\begin{tabular}{|c|c|c|c|c|c|c|c|c|}
\hline \multirow[t]{2}{*}{ Items } & \multicolumn{4}{|c|}{ Treatments } & \multirow[t]{2}{*}{ SEM } & \multicolumn{3}{|c|}{$P$-value } \\
\hline & CON & CSL & ECON & ESL & & SL & ETEC & Interaction \\
\hline \multicolumn{9}{|l|}{ Duodenum } \\
\hline Villus height, $\mu \mathrm{m}$ & $439.83^{b}$ & $573.03^{a}$ & $367.14^{\mathrm{b}}$ & $393.24^{b}$ & 25.47 & 0.07 & 0.01 & 0.21 \\
\hline Crypt depth, $\mu \mathrm{m}$ & 153.13 & 152.28 & 169.47 & 153.70 & 5.66 & 0.49 & 0.46 & 0.53 \\
\hline $\mathrm{V}: \mathrm{C}$ & $2.87^{b}$ & $3.76^{a}$ & $2.17^{c}$ & $2.56^{\mathrm{bc}}$ & 0.16 & 0.01 & 0.00 & 0.18 \\
\hline \multicolumn{9}{|l|}{ Jejunum } \\
\hline Villus height, $\mu \mathrm{m}$ & $397.09^{\mathrm{a}}$ & $407.55^{\mathrm{a}}$ & $252.71^{b}$ & $385.47^{\mathrm{a}}$ & 17.19 & $<0.01$ & $<0.01$ & $<0.01$ \\
\hline Crypt depth, $\mu \mathrm{m}$ & $130.50^{\mathrm{ab}}$ & $100.38^{b}$ & $155.96^{\mathrm{a}}$ & $102.66^{\mathrm{b}}$ & 6.35 & $<0.01$ & 0.17 & 0.24 \\
\hline $\mathrm{V}: \mathrm{C}$ & $3.04^{b}$ & $4.06^{\mathrm{a}}$ & $1.62^{c}$ & $3.75^{\mathrm{ab}}$ & 0.28 & $<0.01$ & 0.01 & 0.14 \\
\hline \multicolumn{9}{|l|}{ Ileum } \\
\hline Villus height, $\mu \mathrm{m}$ & $321.63^{a}$ & $341.32^{\mathrm{a}}$ & $264.15^{\mathrm{b}}$ & $327.45^{\mathrm{a}}$ & 10.82 & 0.04 & 0.08 & 0.27 \\
\hline Crypt depth, $\mu \mathrm{m}$ & $91.01^{b}$ & $88.06^{\mathrm{b}}$ & $138.10^{\mathrm{a}}$ & $92.46^{\mathrm{b}}$ & 6.35 & 0.03 & 0.02 & 0.05 \\
\hline $\mathrm{V}: \mathrm{C}$ & $3.53^{\mathrm{a}}$ & $3.88^{\mathrm{a}}$ & $1.91^{b}$ & $3.54^{\mathrm{a}}$ & 0.22 & 0.01 & 0.01 & 0.05 \\
\hline
\end{tabular}

V:C Villus height:Crypt depth

${ }^{1}$ Mean and total SEM are list in Separate columns, $n=8$

$2 a, b$, c mean values within a row with unlike superscript letters were significantly different $P<0.05$

${ }^{3} C O N$, pigs were fed with a basal diet; CSL, pigs were fed with a SL containing diet, $5 \mathrm{~g} / \mathrm{kg}$; ECON, pigs were fed with a basal diet and challenged by ETEC; ESL, pigs were fed with a SL containing diet and challenged by ETEC 


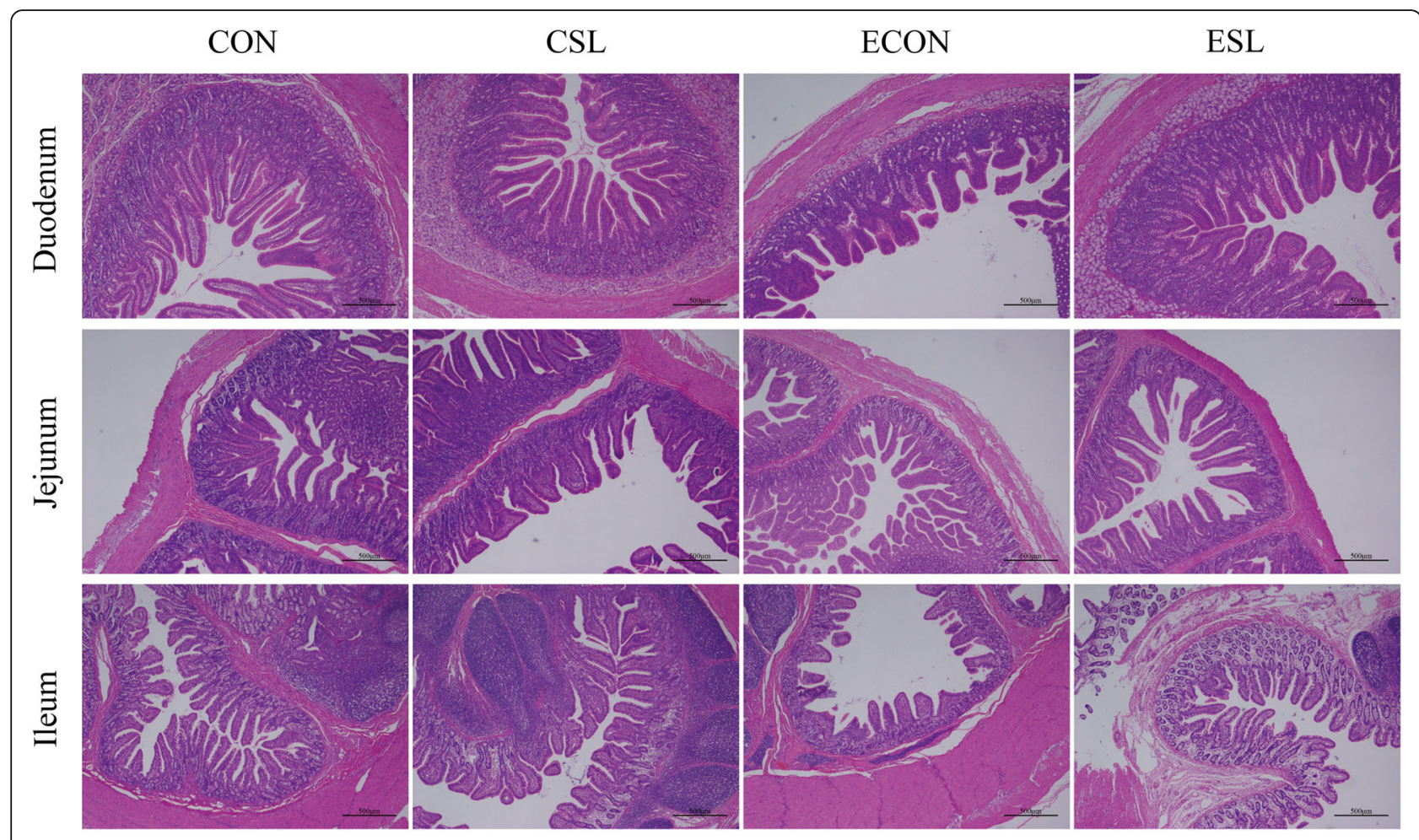

Fig. 2 Effect of SL supplementation on intestinal morphology in weaned pigs upon ETEC challenge $(H \& E ; \times 40)$. CON, pigs were fed with a basal diet; CSL, pigs were fed with a SL containing diet, $5 \mathrm{~g} / \mathrm{kg} ; \mathrm{ESL}$, pigs were fed with a basal diet and challenged by ETEC; ESL, pigs were fed with a SL containing diet and challenged by ETEC

Table 5 Effect of SL supplementation on mucosal enzyme activity in weaned pigs upon ETEC challenge

\begin{tabular}{|c|c|c|c|c|c|c|c|c|}
\hline \multirow[t]{2}{*}{ Items } & \multicolumn{4}{|c|}{ Treatments } & \multirow[t]{2}{*}{ SEM } & \multicolumn{3}{|c|}{$P$-value } \\
\hline & CON & CSL & ECON & ESL & & SL & ETEC & Interaction \\
\hline \multicolumn{9}{|l|}{ Duodenum } \\
\hline AKP, U/g prot & 0.33 & 0.41 & 0.29 & 0.27 & 0.04 & 0.68 & 0.24 & 0.46 \\
\hline Lactase, U/mg prot & $92.95^{\mathrm{bc}}$ & $107.02^{\mathrm{a}}$ & $88.61^{c}$ & $99.02^{\mathrm{ab}}$ & 2.21 & $<0.01$ & 0.06 & 0.54 \\
\hline Sucrase, U/mg prot & $521.99^{b}$ & $596.69^{\mathrm{a}}$ & $498.32^{b}$ & $553.51^{\mathrm{ab}}$ & 14.01 & 0.01 & 0.13 & 0.64 \\
\hline Maltase, U/mg prot & $301.48^{b}$ & $318.06^{\mathrm{a}}$ & $286.45^{c}$ & $312.27^{\mathrm{ab}}$ & 4.18 & $<0.01$ & 0.06 & 0.37 \\
\hline \multicolumn{9}{|l|}{ Jejunum } \\
\hline AKP, U/g prot & 0.21 & 0.20 & 0.15 & 0.24 & 0.02 & 0.17 & 0.66 & 0.07 \\
\hline Lactase, U/mg prot & 86.14 & 88.44 & 85.67 & 85.14 & 1.12 & 0.73 & 0.47 & 0.58 \\
\hline Sucrase, U/mg prot & $497.78^{b}$ & $563.07^{\mathrm{a}}$ & $480.31^{b}$ & $556.50^{\mathrm{a}}$ & 11.06 & $<0.01$ & 0.43 & 0.72 \\
\hline Maltase, U/mg prot & $290.70^{b c}$ & $315.18^{\mathrm{a}}$ & $286.28^{c}$ & $307.49^{a b}$ & 4.18 & 0.01 & 0.40 & 0.82 \\
\hline \multicolumn{9}{|l|}{ lleum } \\
\hline AKP, U/g prot & 0.09 & 0.11 & 0.07 & 0.10 & 0.01 & 0.18 & 0.52 & 0.66 \\
\hline Lactase, U/mg prot & $84.65^{b}$ & $95.90^{\mathrm{a}}$ & $76.55^{c}$ & $89.47^{\mathrm{ab}}$ & 2.15 & $<0.01$ & 0.01 & 0.75 \\
\hline Sucrase, $U / m g$ prot & $513.41^{b c}$ & $534.26^{\mathrm{a}}$ & $506.59^{c}$ & $531.65^{\mathrm{ab}}$ & 4.34 & 0.00 & 0.45 & 0.73 \\
\hline Maltase, U/mg prot & $344.98^{b}$ & $362.95^{\mathrm{a}}$ & $342.57^{\mathrm{b}}$ & $360.23^{\mathrm{a}}$ & 3.16 & 0.00 & 0.59 & 0.97 \\
\hline
\end{tabular}

AKP alkaline phosphatase

${ }^{1}$ Mean and total SEM are list in Separate columns, $n=8$

$2 a$, b, c mean values within a row with unlike superscript letters were significantly different, $P<0.05$

${ }^{3} C O N$, pigs were fed with a basal diet; CSL, pigs were fed with a SL containing diet, $5 \mathrm{~g} / \mathrm{kg}$; ECON, pigs were fed with a basal diet and challenged by ETEC; ESL, pigs were fed with a SL containing diet and challenged by ETEC 
Table 6 Effect of SL supplementation on caecal microbial populations and its products in weaned pigs upon ETEC challenge

\begin{tabular}{|c|c|c|c|c|c|c|c|c|}
\hline \multirow[t]{2}{*}{ Items } & \multicolumn{4}{|c|}{ Treatments } & \multirow[t]{2}{*}{ SEM } & \multicolumn{3}{|c|}{$P$-value } \\
\hline & $\overline{\mathrm{CON}}$ & CSL & ECON & ESL & & $\overline{\mathrm{SL}}$ & ETEC & Interaction \\
\hline \multicolumn{9}{|c|}{ microbial populations, lg (copies/g) } \\
\hline Total bacteria & 11.81 & 11.99 & 11.66 & 12.03 & 0.16 & 0.43 & 0.88 & 0.79 \\
\hline Lactobacillus & $7.89^{\mathrm{bc}}$ & $9.23^{\mathrm{a}}$ & $7.37^{c}$ & $9.11^{\mathrm{a}}$ & 0.28 & $<0.01$ & 0.46 & 0.65 \\
\hline Escherichia coli & $7.73^{\mathrm{b}}$ & $7.43^{\mathrm{b}}$ & $9.67^{\mathrm{a}}$ & $8.42^{\mathrm{b}}$ & 0.27 & 0.05 & $<0.01$ & 0.21 \\
\hline Bifidobacterium & $6.16^{\mathrm{bc}}$ & $7.00^{\mathrm{a}}$ & $5.85^{\mathrm{c}}$ & $6.58^{\mathrm{a}}$ & 0.15 & $<0.01$ & 0.16 & 0.84 \\
\hline Bacillus & $5.75^{\mathrm{b}}$ & $6.63^{\mathrm{a}}$ & $5.71^{\mathrm{b}}$ & $6.57^{\mathrm{a}}$ & 0.16 & $<0.01$ & 0.84 & 0.96 \\
\hline \multicolumn{9}{|l|}{$V F A, \mu g / g$} \\
\hline Acetic acid & $3349.31^{\mathrm{a}}$ & $3669.06^{\mathrm{a}}$ & $2504.41^{b}$ & $3417.64^{\mathrm{a}}$ & 133.74 & 0.01 & 0.02 & 0.18 \\
\hline Propanoic acid & $1987.11^{\mathrm{a}}$ & $2103.38^{a}$ & $1358.17^{b}$ & $2082.78^{a}$ & 97.30 & 0.01 & 0.05 & 0.06 \\
\hline Butyric acid & $649.89^{b}$ & $1150.57^{a}$ & $601.12^{\mathrm{b}}$ & $1097.03^{a}$ & 90.68 & $<0.01$ & 0.71 & 0.99 \\
\hline
\end{tabular}

VFA volatile fatty acids

${ }^{1}$ Mean and total SEM are list in Separate columns, $n=8$

${ }^{2} \mathrm{a}$, b, c mean values within a row with unlike superscript letters were significantly different, $P<0.05$

${ }^{3} \mathrm{CON}$, pigs were fed with a basal diet; CSL, pigs were fed with a SL containing diet, $5 \mathrm{~g} / \mathrm{kg}$; ECON, pigs were fed with a basal diet and challenged by ETEC; ESL, pigs were fed with a SL containing diet and challenged by ETEC

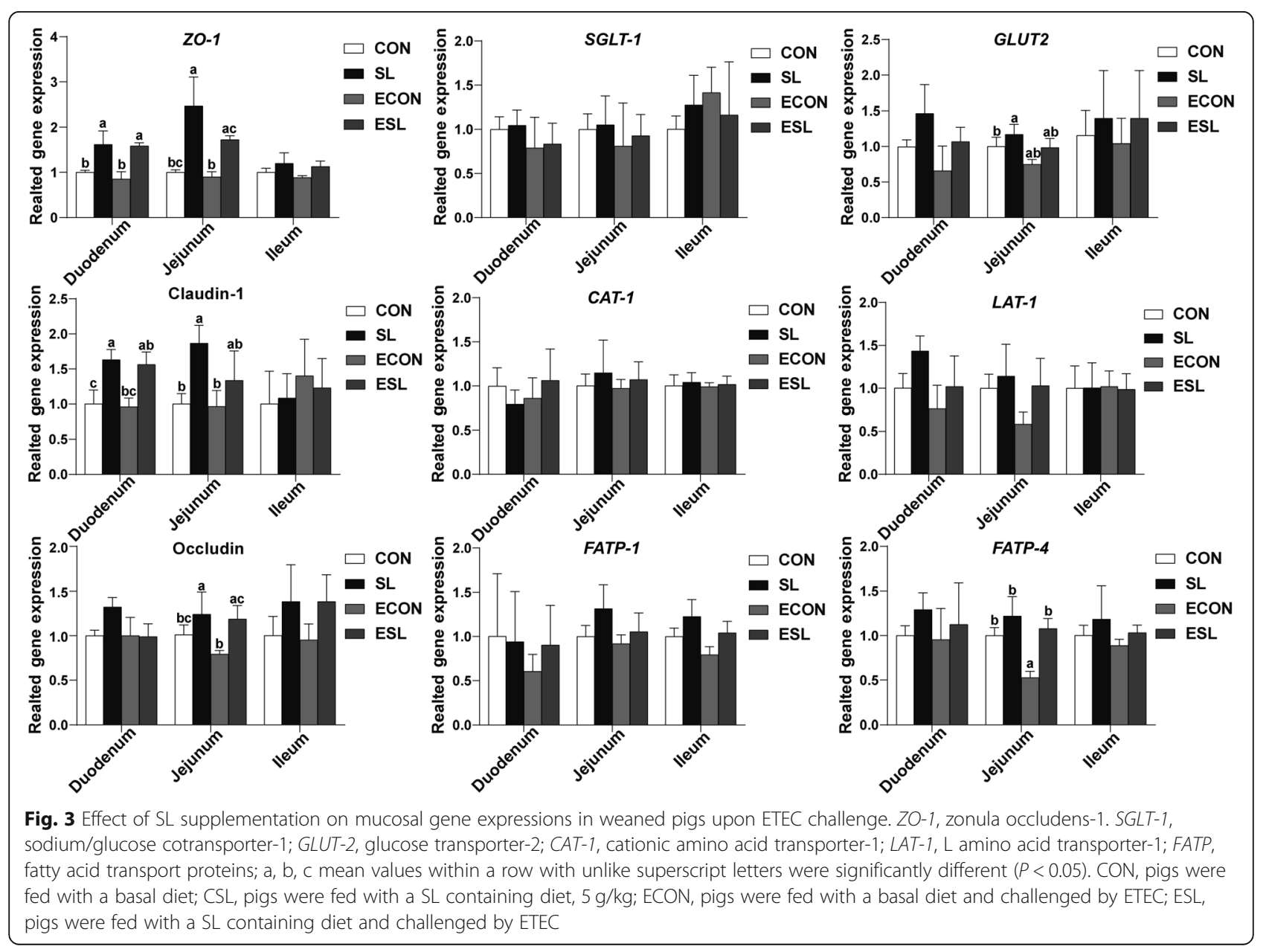


digestion and absorption function [38]. Villi are critical components of the digestive tract, their geometry and V: $\mathrm{C}$ ratio provides an indicator of the absorptive capacity of the small intestine [39]. In this study, ETEC challenge decreased the villus height and the $\mathrm{V}: \mathrm{C}$ in the jejunum and ileum. However, SL significantly improved the intestinal morphology by increasing the villus height and the $\mathrm{V}: \mathrm{C}$ ratio. This is probably due to the fact that SL reduced the secretion of inflammatory cytokines (such as TNF- $\alpha$, IL-1 $\beta$, IL-6) which have been shown to promote apoptosis of the intestinal epithelial cells [40]. Changes of the intestinal morphology is usually accompanied by the digestive enzyme activity in brush border of the intestinal epithelium [41]. In the present study, ETEC challenge decreased the activities of maltase and lactase in the duodenum and ileum. However, SL supplementation significantly elevated their activities both in the non-challenged and ETEC-challenged pigs.

MOs are known to support the growth of beneficial microorganisms in the large intestine, especially the Bifidobacterium species, a dominant species in breast-fed infants [42]. As one of the most abundant components of the MOs, SL is highly resistant to hydrolase in the digestive tract and can reach the hindgut in an intact form, where it will be fermented by bacteria to release free sialic acid that can serve as a substrate for bacterial energy metabolism [43, 44]. Recent studies showed that SL can inhibit the adhesion of E. coli to Caco-2 cells and increase the abundance of Bifidobacterium and Lactobacilli in the infants and adults feces [45, 46]. Similar result was obtained in this study and we found that SL significantly increased the abundance of beneficial bacteria such as Lactobacilli, Bacillus, and Bifidobacterium in the non-challenged pigs. Importantly, SL not only decreased the abundance of Escherichia coli, but also increased the abundance of Lactobacilli, Bifidobacterium and Bacillus in the ETEC-challenged pigs. Previous study indicated that MOs including the SL are structurally similar to the polysaccharide on the surface of intestinal epithelial cells which can act as an analog of bacterial lectin ligand and block bacterial attachment [45]. Moreover, SL may also change the glycosylation on the surface of the intestinal epithelial cells, and thereby affecting the attachment and colonization of bacteria [47]. Nondigestible oligosaccharides, including SL, can be utilized by microorganisms in large intestine and generate various short-chain fatty acids (SCFA) [48]. SCFA, especially butyric acid, has been shown to play an important role in modulating inflammatory response and intestinal barrier functions [49]. In the present study, SL significantly elevated the concentration of butyric acid in the ETEC-challenged pigs. The result is consistent with previous studies that beneficial microorganisms such as the Lactobacillus and Bifidobacterium can increase the butyric acid production, which may contribute to reduced generation of pro-inflammatory cytokines such as the TNF- $\alpha$ [50]. Moreover, SL supplementation also significantly elevated the concentration of acetic acid and propionic acid in the ETEC challenged pigs, indicating that SL performs several physiological roles in regulating intestinal permeability, inflammation control and immunological function [51].

Tight junctions are composed of transmembrane barrier proteins (e.g., claudins and occludin), cytoplasmic scaffold proteins (e.g., ZO family), and adhesion molecules, which play a key role in maintaining intestinal permeability [52]. However, various enteric pathogens can alter the distribution of tight junction proteins and impair the permeability of the intestinal epithelium [53]. Previous study indicated that ETEC infection decreased the expression levels of tight junction proteins such as the ZO-1, occluding, and claudins [54]. In the present study, we found that SL supplementation significantly elevated the expression levels of ZO-1 and occludin-1 in the jejunal epithelium upon ETEC challenge. Moreover, SL also elevated the expression levels of GLUT2 and FATP-4 in the jejunal epithelium. GLUT-2 is one of the major transporters for glucose absorption, and the FATP-4 is responsible for long chain fatty acids uptake in enterocytes $[55,56]$. These results indicated that dietary SL supplementation is helpful to improve intestinal integrity and epithelial functions in weaned pigs upon ETEC challenge.

In the present study, we found that SL has beneficial effects on intestinal morphology, expression of tight junction proteins and inflammatory cytokines, probiotic colonization and VFA production. Previous studies have shown that probiotics such as Bifidobacterium and Bacillushis have a protective effect on the intestinal barrier and can downregulate the expression levels of inflammatory cytokines [5658]. Therefore, we hypothesized that SL could exert a probiotic effect by promoting probiotic colonization, increasing microbial fermentation and breakdown of complex carbohydrates [56], and increasing VFA production.

\section{Conclusion}

Dietary SL supplementation improves the growth performance and alleviates ETEC-induced intestinal injury in the weaned pigs, which was associated with suppressed secretion of inflammatory cytokines and elevated serum immunoglobulins, as well as improved intestinal epithelium functions and microbiota. The beneficial effects of SL on the intestinal integrity and epithelium functions could make it an attractive prebiotic in the use of animal nutrition and feed industry.

\section{Abbreviations}

ADFI: Average daily feed intake; ADG: Average daily gain; AIA: Acid insoluble ash; AKP: Alkaline phosphatase; CAT-1: Cationic amino acid transporter-1; 
CON: Pigs were fed with a basal diet; CP: Crude protein; CSL: Pigs were fed with basal diet containing $5 \mathrm{~g} / \mathrm{kg} \mathrm{SL}$ product; Ct: Cycle threshold; DCs: Dendritic cells; DM: Dry matter; ECON: Pigs were fed with a basal diet and challenged by ETEC; EE: Ether extract; ESL: Pigs were fed with basal diet containing $5 \mathrm{~g} / \mathrm{kg}$ SL product and challenged by ETEC; ETEC: Enterotoxigenic Escherichia coli; FATP: Fatty acid transport proteins; Fuc: Fucose;

Gal: Galactose; GE: Gross energy; Glc: Glucose; GlcNAc: N-acetylglucosamine; GLM: General linear model; GLUT-2: Glucose transporter-2; IL-1 B: Interleukin1B; IL-6: Interleukin-6; IgA: Immunoglobulins A; IgG: Immunoglobulins G; IgM: Immunoglobulins M; LAT-1: L amino acid transporter-1; LB: Luria-Bertani; MOs: Milk oligosaccharides; Neu5Ac: N-acetylneuraminic acid; PBS: Phosphate buffered saline; PWD: Post weaning diarrhea; SCFA: Short chain fatty acid; SGLT-1: Sodium/glucose cotransporter-1; Sia: Sialic acid; SL: Sialyllactose; TJ: Tight junctions; TNF-a: Tumor necrosis factor-a; V:C: Villus height : crypt depth; VFA: Volatile fatty acids; ZO-1: Zonula occludens-1

\section{Supplementary Information}

The online version contains supplementary material available at https://doi. org/10.1186/s40104-022-00673-8.

Additional file 1 Table S1. Sequences of primers for genes and

intestinal bacteria.

\section{Acknowledgments}

We thank the Danish company Glycom and Vigsnæs Louise for their generous donation, and Huifen Wang, Fali Wu, and Yuankang Zhou for their help during the animal trial and sample collections.

\section{Authors' contributions}

$J H$ conceived and designed the experiments. QD performed animal trial and wrote the manuscript. DC, BY, XM, ZP, JY, HY, and ZH performed biochemical analysis. JL, LY, and $H Y$ gave constructive comments for the results and discussion of the manuscript. All authors have read and approved the final manuscript.

\section{Funding}

This work was supported by the National Natural Science Foundation of China (31972599), and the Key Research and Development Program of Sichuan Province (2020YFN0147).

\section{Availability of data and materials}

The data used to support the findings of this study are available from the corresponding author upon request.

\section{Declarations}

\section{Ethics approval and consent to participate}

All experimental protocols used in the animal experiment were approved by the Institutional Animal Care and Use Committee of Sichuan Agricultural University (No.20181105). SL was donated from the research donation project of glycom company in Denmark.

\section{Consent for publication}

Not applicable.

\section{Competing interests}

The authors declare that there are no conflicts of interest.

Received: 12 September 2021 Accepted: 5 January 2022 Published online: 03 March 2022

\section{References}

1. Wu S, Zhang F, Huang Z, Liu H, Xie C, Zhang J, et al. Effects of the antimicrobial peptide cecropin $A D$ on performance and intestinal health in weaned piglets challenged with Escherichia coli. Peptides. 2012;35(2):22530. https://doi.org/10.1016/j.peptides.2012.03.030.

2. Kaper JB, Nataro JP, Mobley HL. Pathogenic Escherichia coli. Nat Rev Microbiol. 2004;2(2):123-40. https://doi.org/10.1038/nrmicro818.
3. Günther $C$, Neumann $H$, Neurath MF, Becker C. Apoptosis, necrosis and necroptosis: cell death regulation in the intestinal epithelium. Gut. 2013; 62(7):1062-71. https://doi.org/10.1136/gutjnl-2011-301364.

4. Bhandari SK, Xu B, Nyachoti CM, Giesting DW, Krause DO. Evaluation of alternatives to antibiotics using an Escherichia coli K88+ model of piglet diarrhea: effects on gut microbial ecology. J Anim Sci. 2008;86(4):836-47. https://doi.org/10.2527/jas.2006-822.

5. Barton MD. Antibiotic use in animal feed and its impact on human healt. Nutr Res Rev. 2000;13(2):279-99. https://doi.org/10.1079/095442200108729106.

6. Chen W, Mi J, Lv N, Gao J, Cheng J, Wu R, et al. Lactation stage-dependency of the sow milk microbiota. Front Microbiol. 2018;9:945. https://doi.org/10.33 89/fmicb.2018.00945.

7. Ballard O, Morrow AL. Human milk composition: nutrients and bioactive factors. Pediatr Clin North Am. 2013;60(1):49-74. https://doi.org/10.1016/j. pcl.2012.10.002.

8. Samuel TM, Binia A, de Castro CA, Thakkar SK, Billeaud C, Agosti M, et al. Impact of maternal characteristics on human milk oligosaccharide composition over the first 4 months of lactation in a cohort of healthy European mothers. Sci Rep. 2019;9(1):11767. https://doi.org/10.1038/s41598019-48337-4.

9. Bode L. Human milk oligosaccharides: every baby needs a sugar mama. Glycobiology. 2012;22(9):1147-62. https://doi.org/10.1093/glycob/cws074.

10. Cheng $L, X u Q$, Yang $K, H e J$, Chen D, Du Y, et al. Annotation of porcine milk oligosaccharides throughout lactation by hydrophilic interaction chromatography coupled with quadruple time of flight tandem mass spectrometry. Electrophoresis. 2016;37(11):1525-31. https://doi.org/10.1002/ elps.201500471.

11. Tarr AJ, Galley JD, Fisher SE, Chichlowski M, Berg BM, Bailey MT. The prebiotics 3'Sialyllactose and 6'Sialyllactose diminish stressor-induced anxiety-like behavior and colonic microbiota alterations: evidence for effects on the gut-brain axis. Brain Behav Immun. 2015;50:166-77. https://doi.org/1 0.1016/j.bbi.2015.06.025.

12. Marcobal A, Barboza M, Froehlich JW, Block DE, German JB, Lebrilla CB, et al. Consumption of human milk oligosaccharides by gut-related microbes. J Agric Food Chem. 2010;58(9):5334-40. https://doi.org/10.1021/jf9044205.

13. Newburg DS, Ruiz-Palacios GM, Morrow AL. Human milk glycans protect infants against enteric pathogens. Annu Rev Nutr. 2005;25(1):37-58. https:// doi.org/10.1146/annurev.nutr.25.050304.092553.

14. Wang B, Brand-Miller J, McVeagh P, Petocz P. Concentration and distribution of sialic acid in human milk and infant formulas. Am J Clin Nutr. 2001;74(4):510-5. https://doi.org/10.1093/ajcn/74.4.510.

15. Hester SN, Chen X, Li M, Monaco MH, Comstock SS, Kuhlenschmidt TB, et al. Human milk oligosaccharides inhibit rotavirus infectivity in vitro and in acutely infected piglets. Br J Nutr. 2013;110(7):1233-42. https://doi.org/10.1 017/S0007114513000391.

16. Gao $Y$, Han F, Huang $X$, Rong $Y, Y i$, Wang $Y$. Changes in gut microbial populations, intestinal morphology, expression of tight junction proteins, and cytokine production between two pig breeds after challenge with Escherichia coli K88: a comparative study. J Anim Sci. 2013;91(12):5614-25. https://doi.org/10.2527/jas.2013-6528.

17. Li M, Monaco MH, Wang M, Comstock SS, Kuhlenschmidt TB, Fahey GC, et al. Human milk oligosaccharides shorten rotavirus-induced diarrhea and modulate piglet mucosal immunity and colonic microbiota. ISME J. 2014; 8(8):1609-20. https://doi.org/10.1038/ismej.2014.10.

18. Liu P, Piao XS, Thacker PA, Zeng ZK, Li PF, Wang D, et al. Chitooligosaccharide reduces diarrhea incidence and attenuates the immune response of weaned pigs challenged with Escherichia coli K88. J Anim Sci. 2010;88(12):3871-9. https://doi.org/10.2527/jas.2009-2771.

19. National Research Council (U.S.). Nutrient requirements of swine. 11th ed. Washington D.C: National Academies Press; 2012.

20. Latimer GW Jr. Official methods of analysis of AOAC international. 20th ed. Rockville, MD: AOAC International; 2016.

21. Yang Y, lji PA, Kocher A, Mikkelsen LL, Choct M. Effects of dietary mannanoligosaccharide on growth performance, nutrient digestibility and gut development of broilers given different cereal-based diets. J Anim Physiol Anim Nutr. 2008;92(6):650-9. https://doi.org/10.1111/j.1439-0396.2007.00761.x.

22. Wan J, Zhang J, Chen D, Yu B, Mao X, Zheng P, et al. Alginate oligosaccharide-induced intestinal morphology, barrier function and epithelium apoptosis modifications have beneficial effects on the growth performance of weaned pigs. J Anim Sci Biotechnol. 2018;9:58. https://doi. org/10.1186/s40104-018-0273-x. 
23. King MR, Morel PCH, Revell DK, Pluske JR, Birtles MJ. Dietary bovine colostrum increases villus height and decreases small intestine weight in early-weaned pigs. Asian Australas J Anim Sci. 2008;21(4):567-73. https://doi. org/10.5713/ajas.2008.70491.

24. Franklin MA, Mathew AG, Vickers JR, Clift RA. Characterization of microbial populations and volatile fatty acid concentrations in the jejunum, ileum, and ce-cum of pigs weaned at 17 vs 24 days of age. J Anim Sci. 2002; 80(11):2904-10. https://doi.org/10.2527/2002.80112904x.

25. Fleige S, Walf V, Huch S, Prgomet C, Sehm J, Pfaffl MW. Comparison of relative $m R N A$ quantification models and the impact of RNA integrity in quantita-tive real-time RT-PCR. Biotechnol Lett. 2006;28(19):1601-13. https:// doi.org/10.1007/s10529-006-9127-2.

26. Le Doare K, Holder B, Bassett A, Pannaraj PS. Mother's Milk: A purposeful contribution to the development of the infant microbiota and immunity. Front Immunol. 2018;9:361. https://doi.org/10.3389/fimmu.2018.00361.

27. Vass RA, Kemeny A, Dergez T, Ertl T, Reglodi D, Jungling A, et al. Distribution of bioactive factors in human milk samples. Int Breastfeed J. 2019;14(1):9. https://doi.org/10.1186/s13006-019-0203-3.

28. Nijman RM, Liu Y, Bunyatratchata A, Smilowitz JT, Stahl B, Barile D. Characterization and quantification of oligosaccharides in human milk and infant formula. J Agric Food Chem. 2018;66(26):6851-9. https://doi.org/10.1 021/acs.jafc.8b01515

29. Patki S, Kadam S, Chandra V, Bhonde R. Human breast milk is a rich source of multipotent mesenchymal stem cells. Hum Cell. 2010;23(2):35-40. https:// doi.org/10.1111/j.1749-0774.2010.00083.x.

30. Meki AR, Saleem TH, Al-Ghazali MH, Sayed AA. Interleukins -6, -8 and -10 and tumor necrosis factor-alpha and its soluble receptor I in human milk at different periods of lactation. Nutr Res. 2003;23:845-55. https://doi.org/10.1 016/S0271-5317(03)00035-6.

31. Savel'ev AN, Kanyshkova TG, Kulminskaya AA, Buneva VN, Eneyskaya EV, Filatov MV, et al. Amylolytic activity of lgG and slgA immunoglobulins from human milk. Clin Chim Acta. 2001;314(1-2):141-52. https://doi.org/10.1016/ S0009-8981(01)00691-X.

32. Gila-Diaz A, Arribas SM, Algara A, Martín-Cabrejas MA, López de Pablo ÁL, Sáenz de Pipaón $M$, et al. A review of bioactive factors in human breastmilk: a focus on prematurity. Nutrients. 2019;11(6):1307. https://doi.org/10.3390/ nu11061307.

33. Zhang X, Liu Y, Liu L, Li J, Du G, Chen J. Microbial production of sialic acid and sialylated human milk oligosaccharides: advances and perspectives. Biotechnol Adv. 2019;37(5):787-800. https://doi.org/10.1016/j.biotechadv.2019.04.011.

34. Markina YV, Gerasimova EV, Markin AM, Glanz VY, Wu W-K, Sobenin IA, et al. Sialylated immunoglobulins for the treatment of immuno-inflammatory diseases. Int J Mol Sci. 2020;21(15):5472. https://doi.org/10.3390/ijms21155472.

35. Zelnickova P, Leva L, Stepanova H, Kovaru F, Faldyna M. Age-dependent changes of proinflammatory cytokine production by porcine peripheral blood phagocytes. Vet Immunol Immunopathol. 2008;124(3-4):367-78. https://doi.org/10.1016/j.vetimm.2008.04.016.

36. Zenhom M, Hyder A, de Vrese M, Heller KJ, Roeder T, Schrezenmeir J. Prebiotic oligosaccharides reduce proinflammatory cytokines in intestinal Caco-2 cells via activation of PPARY and peptidoglycan recognition protein 3. J Nutr. 2011;141(5):971-7. https://doi.org/10.3945/jn.110.136176.

37. Gustavo Hermes R, Molist F, Francisco Pérez J, Gómez de Segura A, Ywazaki M, Davin R, et al. Casein glycomacropeptide in the diet may reduce Escherichia coli attachment to the intestinal mucosa and increase the intestinal lactobacilli of early weaned piglets after an enterotoxigenic $E$. coli K88 challenge. Br J Nutr. 2013;109:1001-12. https://doi.org/10.1017/ S0007114512002978.

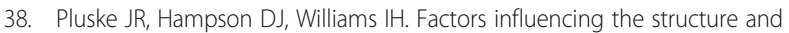
function of the small intestine in the weaned pig: a review. Livest Prod Sci. 1997;51(1-3):215-36. https://doi.org/10.1016/S0301-6226(97)00057-2.

39. Xu Q, Jitkaew S, Choksi S, Kadigamuwa C, Qu J, Choe M, et al. The cytoplasmic nuclear receptor RARy controls RIP1 initiated cell death when CIAP activity is inhibited. Nat Commun. 2017;8(1):425. https://doi.org/10.1038/ s41467-017-00496-6.

40. Wan J, Jiang F, Xu Q, Chen D, Yu B, Huang Z, et al. New insights into the role of chitosan oligosaccharide in enhancing growth performance, antioxidant capacity, immunity and intestinal development of weaned pigs. RSC Adv. 2017:7(16):9669-79. https://doi.org/10.1039/C7RA00142H.

41. Kirmiz N, Robinson RC, Shah IM, Barile D, Mills DA. Milk Glycans and their interaction with the infant-gut microbiota. Annu Rev Food Sci Technol. 2018;9(1):429-50. https://doi.org/10.1146/annurev-food-030216-030207.
42. Gnoth MJ, Kunz C, Kinne-Saffran E, Rudloff S. Human milk oligosaccharides are minimally digested in vitro. J Nutr. 2000;130(12):3014-20. https://doi. org/10.1093/jn/130.12.3014

43. Nöhle U, Schauer R. Metabolism of sialic acids from exogenously administered sialyllactose and mucin in mouse and rat. Hoppe Seylers Z Physiol Chem. 1984;365(2):1457-67. https://doi.org/10.1515/bchm2.1984.3 65.2.1457

44. Bode L. Human milk oligosaccharides: prebiotics and beyond. Nutr Rev. 2009:67(Suppl 2):S183-91. https://doi.org/10.1111/j.1753-4887.2009.00239.x.

45. Perdijk $O$, van Baarlen P, Fernandez-Gutierrez MM, van den Brink E, Schuren FHJ, Brugman S, et al. Sialyllactose and galactooligosaccharides promote epithelial barrier functioning and distinctly modulate microbiota composition and short chain fatty acid production in vitro. Front Immunol. 2019;10:94. https://doi.org/10.3389/fimmu.2019.00094.

46. Sakarya S, Göktürk C, Oztürk T, Ertugrul MB. Sialic acid is required for nonspecific adherence of salmonella enterica ssp. enterica serovar Typhi on Caco-2 cells. FEMS Immunol Med Microbiol. 2010;58(3):330-5. https://doi. org/10.1111/j.1574-695X.2010.00650.X.

47. Ma N, Tian $Y$, Wu Y, Ma X. Contributions of the interaction between dietary protein and gut microbiota to intestinal health. Curr Protein Pept Sci. 2017; 18(8):795-808. https://doi.org/10.2174/1389203718666170216153505.

48. Hamer HM, Jonkers D, Venema K, Vanhoutvin S, Troost FJ, Brummer R-J. Review article: the role of butyrate on colonic function. Aliment Pharm Ther. 2008;27(2):104-19. https://doi.org/10.1111/j.1365-2036.2007.03562.x.

49. Busche R, Hass R, Reale E, Luciano L, Engelhardt W. Lack of butyrate is associated with induction of bax and subsequent apoptosis in the proximal colon of guinea pig. Biochem Soc T. 1996;24(4):574S. https://doi.org/10.1 042/bst024574s

50. Nancey S, Moussata D, Graber I, Claudel S, Saurin J-C, Flourié B. Tumor necrosis factor alpha reduces butyrate oxidation in vitro in human colonic mucosa: a link from inflammatory process to mucosal damage? Inflamm Bowel Dis. 2005;11(6):559-66. https://doi.org/10.1097/01.MIB.0000161918.04 $760 . f 3$.

51. Murugesan S, Nirmalkar K, Hoyo-Vadillo C, García-Espitia M, Ramírez-Sánchez D, García-Mena J. Gut microbiome production of short-chain fatty acids and obesity in children. Eur J Clin Microbiol Infect Dis. 2018;37(4):621-5. https:// doi.org/10.1007/s10096-017-3143-0.

52. Dokladny K, Zuhl MN, Moseley PL. Intestinal epithelial barrier function and tight junction proteins with heat and exercise. J Appl Physiol. 2016;120(6): 692-701. https://doi.org/10.1152/japplphysiol.00536.2015.

53. Tong L, Wang Y, Wang Z, Liu W, Sun S, Li L, et al. Propionate ameliorates dextran sodium sulfate-induced colitis by improving intestinal barrier function and reducing inflammation and oxidative stress. Front Pharmacol. 2016:7:253. https://doi.org/10.3389/fphar.2016.00253.

54. Yu E, Chen D, Yu B, Huang Z, Mao X, Zheng P, et al. Manno-oligosaccharide attenuates inflammation and intestinal epithelium injury in weaned pigs upon enterotoxigenic Escherichia coli K88 challenge. Br J Nutr. 2020;126(7): 1-10. https://doi.org/10.1017/S0007114520004948.

55. Sangild PT, Tappenden KA, Malo C, Petersen YM, Elnif J, Bartholome AL, et al. Glucagon-like peptide 2 stimulates intestinal nutrient absorption in parenterally fed newborn pigs. J Pediatr Gastr Nutr. 2006;43(2):160-7. https://doi.org/10.1097/01.mpg.0000228122.82723.1b.

56. Macfarlane S, Macfarlane GT. Regulation of short-chain fatty acid production. Proc Nutr Soc. 2003;62(1):67-72. https://doi.org/10.1079/PNS2 002207.

57. Tang W, Qian Y, Yu B, Zhang T, Gao J, He J, et al. Effects of Bacillus subtilis DSM32315 supplementation and dietary crude protein level on performance, gut barrier function and microbiota profile in weaned piglets1. J Anim Sci. 2019;97(5):2125-38. https://doi.org/10.1093/jas/skz090.

58. Fujie H, Villena J, Tohno M, Morie K, Shimazu T, Aso H, et al. Toll-like receptor-2activating bifidobacteria strains differentially regulate inflammatory cytokines in the porcine intestinal epithelial cell culture system: finding new antiinflammatory immunobiotics. FEMS Immunol Med Microbiol. 2011;63(1):12939. https://doi.org/10.1111/j.1574-695X.2011.00837.x. 